\title{
Environmental disclosure and sentiment analysis: state of the art and opportunities for public- sector organisations
}

\author{
Laura Rocca \\ Department of Economics and Management, University of Brescia, \\ Brescia, Italy \\ Davide Giacomini \\ The Faculty of Business and Law, The Open University Business School, UK, and \\ Paola Zola \\ IIT-CNR, Pisa, Italy
}

\begin{abstract}
Purpose - Because of the expansion of the internet and Web 2.0 phenomenon, new challenges are emerging in the disclosure practises adopted by organisations in the public-sector. This study aims to examine local governments' (LGOs) use of social media (SM) in disclosing environmental actions/plans/information as a new way to improve accountability to citizens to obtain organisational legitimacy and the related sentiment of citizens' judgements.
\end{abstract}

Design/methodology/approach - This paper analyses the content of 39 Italian LGOs' public pages on Facebook. After the distinction between five classes of environmental issues (air, water, energy, waste and territory), an initial study is performed to detect possible sub-topics applying latent Dirichlet allocation. Having a list of posts related to specific environmental themes, the researchers computed the sentiment of citizens' comments. To measure sentiment, two different approaches were implemented: one based on a lexicon dictionary and the other based on convolutional neural networks.

Findings - Facebook is used by LGOs to disclose environmental issues, focussing on their main interest in obtaining organisational legitimacy, and the analysis shows an increasing impact of Web 2.0 in the direct interaction of LGOs with citizens. On the other hand, there is a clear divergence of interest on environmental topics between LGOs and citizens in a dialogic accountability framework.

Practical implications - Sentiment analysis (SA) could be used by politicians, but also by managers/ entrepreneurs in the business sector, to analyse stakeholders' judgements of their communications/ actions and plans on corporate social responsibility. This tool gives a result on time (i.e. not months or years after, as for the reporting system). It is cheaper than a survey and allows a first "photograph" of stakeholders' sentiment. It can also be a useful tool for supporting, developing and improving environmental reporting.

Originality/value - To the best of the authors' knowledge, this paper is one of the first to apply SA to environmental disclosure via SM in the public sphere. The study links modern techniques in natural language

(C) Laura Rocca, Davide Giacomini and Paola Zola. Published by Emerald Publishing Limited. This article is published under the Creative Commons Attribution (CC BY 4.0) licence. Anyone may reproduce, distribute, translate and create derivative works of this article (for both commercial and non-commercial purposes), subject to full attribution to the original publication and authors. The full terms of this licence may be seen at http://creativecommons.org/licences/by/4.0/legalcode

Disclosure and sentiment analysis

Received 12 September 2019 Revised 21 March 2020

9 June 2020

21 July 2020

Accepted 22 July 2020 
MEDAR 29,3

processing and machine learning with the important aspects of environmental communication between LGOs and citizens.

Keywords Facebook, Sentiment analysis, Natural language processing, Local governments, Environment, Organisational legitimacy, Dialogical accountability

Paper type Research paper

\section{Introduction}

New challenges emerge in communication practises in the public context: posts, messages and comments on social media (SM) platforms tell the story of everyday political and civilsociety life. In recent years, there has been an explosion of freely opinionated texts. Web 2.0, blogs and microblogs have changed the way people communicate, moving from passive internet usage to an active approach with content creation. In 2018, the world population accounted for around 7 billion people, and the number of active SM (Facebook, Twitter and Instagram) users was around 3 billion; thus, around $43 \%$ of the active world population were using internet and Web 2.0 platforms to communicate.

The impact of this novel way of communicating for general purposes and also environmental fields determines the grow of researches measuring the sentiment included in the messages leading to the so-calling "Sentiment Analysis" (SA). In particular, this study analyses the use of SM for environmental disclosure by Italian local governments (LGOs). The reason for this choice lies in a previous study on the diffusion of sustainability reporting by Italian LGOs (Giacomini et al., 2018), demonstrating that sustainability reporting practises among LGOs are declining. In 2009, 11\% of Italian municipalities published a sustainability report, in 2013 only 4\%. The main motivation declared by LGOs was the search for cost reductions that represented a barrier to sustainability report preparation in terms of time and staff availability (Giacomini et al., 2018, p. 14). Linking these findings with the increasing use of SM platforms leads to the recognition that new channels of communication have to be studied to understand the potential for new forms of environmental accountability (Russell et al., 2017).

We chose to study LGOs because their level of government is closest to citizens' daily lives. LGOs' actions and plans have a direct impact on territories and people, and they also play a critical role in educating the local community to promote sustainability in their local area (Agenda 21 Action Plan, 1992). The concept of sustainable development as a "process of change in which the exploitation of resources, the direction of investments, the orientation of technological development and institutional change are all in harmony and enhance both current and future potential to meet human needs and aspirations" (Brundtland Report, 1987, p. 30) reveals a government's commitment to foster this change. Thus, LGOs play a crucial role and deserve more attention.

We chose Italy as an empirical setting for several reasons. Firstly, Italy has a Facebook usage rate in line with that of the main Western countries, and the Italian legal system provides numerous environmental functions for municipalities. Secondly, the number of large Italian municipalities is high, which favours a significant collection of data (Agostino, 2013). Thirdly, the authors are more familiar with the identification of Italian keywords in the environmental field, which is a relevant issue in textual analysis. Finally, there are already some studies on the use of Facebook in LGOs, confirming the validity of the empirical setting (Gesuele, 2016; Agostino and Arnaboldi, 2016; Manetti and Bellucci, 2016; Agostino, 2013).

Our focus on environmental matters is twofold. Firstly, LGOs have precise responsibilities in Italy, from waste disposal to air pollution control, to the decision to create new landfills; their awareness of environmental issues is therefore relevant. Secondly, environmental sustainability (ES) is seen as perhaps the most paradigmatic societal challenge requiring citizens' co-productive efforts to obtain a successful implementation of environmental policies (Bremer and Meisch, 2017) 
as involvement of citizens is a key component of the European Union's 7th Environmental Action Programme (European Union, 2014).

In this context, SM, compared to traditional disclosure systems, might be seen as a powerful tool that gives citizens the opportunity to participate in governance practises (Mergel, 2012). Following Mergel (2013), governments can exploit SM technologies to increase transparency, support inter- and intra-organisational collaboration and enable innovative forms of public participation and engagement. The use and support of SM platforms in the construction of dialogic accounting systems is the framework used to analyse the interactions between LGO disclosure and citizens' participation or reactions (Manetti and Bellucci, 2016; Manetti et al., 2016; Bellucci and Manetti, 2017).

Recent research focuses on the new concept of $e$-government, analysing the interaction between government and citizens on SM at different levels, such as political parties, national and LGOs, with respect to different topics (see Section 2). However, as far as we know, no study has been conducted in investigating the interaction between citizens and LGOs on environmental disclosure via SM by exploring the sentiment of these communications.

The analysis was conducted by analysing Italian LGOs' official pages on Facebook and the relative interaction with the public. The methodological technique is SA, which involves the study of the emotions contained in a textual message. This can be a very powerful tool for different fields such as marketing campaigns (Rambocas et al., 2013) or event detection (Sakaki et al., 2010).

Our research aims to understand the potential contributions of an SM platform in the construction of a dialogic accountability system and the underlying purpose of that approach. As far as we know, this is the first time SA has been applied to public organisations to study the interests and emotions of citizens towards LGOs' disclosure on environmental issues. This contributes to the call for studies on new challenges in disclosing systems (Lodhia, 2018; Parvez et al., 2018; Russell et al., 2017; Lai and Stacchezzini, 2019; Suárez-Rico et al., 2019; Giacomini et al., 2020).

The paper is structured as follows: Section 2 briefly reviews the main literature on SM in the public sector and describes the theoretical background. In Section 3, the paper defines the steps of the analysis and the models applied. Section 4 highlights the main findings of this study. Section 5 offers discussions of the results, and Section 6 concludes the paper.

\section{Theoretical background}

The section is divided into two paragraphs: the first illustrates a literature review on the Italian Governments' SM communications and interactions, and the second presents the theoretical framework applied in this paper.

\subsection{Literature review on government social media interactions}

Several investigations were conducted to evaluate the online communications of sample governments (Agostino, 2013; Hofmann et al., 2013; Reilly and Hynan, 2014; Zavattaro et al., 2015; Bonsòn et al., 2015; Bellstrom et al., 2016; Reddick et al., 2017; Haro-de Rosario et al., 2018). Table 1 summarises previous work that analysed government-citizen interaction on SM. As Table 1 shows, a wide range of analyses was conducted around the globe, either focussing on the full list of LGOs in a specific country (Sandoval-Almazan and Gil-Garcia, 2012), government departments (Unsworth and Townes, 2012) or government institutions from specific cities (Wirtz et al., 2018).

However, as argued by Reddick et al. (2017), a lack of research on the potential role of public feedback still exists. E-participation is defined as citizens' voluntary participation in public administration through online platforms, which encourages two-way communication between governments and its subjects (Reddick et al., 2017). 
MEDAR 29,3

A recent study proposed by Bonsòn et al. (2015) highlights that regarding the public's e-participation, Facebook shows a higher level of citizens' engagement with local government, especially when resident's posts are promoted. In fact, as Table 1 shows, most of the work on citizens and government interactions used Facebook as a data source because it provides the opportunity to examine direct government disclosure as well as member reactions in relation to the specific item. Another widely used SM platform is Twitter (Alam and Lucas, 2011; Hubert et al., 2018); however, some researchers have conducted analyses merging various information sources. For instance, Agostino (2013), Ellison and Hardey (2014) and Wirtz et al. (2018) also include data from YouTube and Flickr.

Mergel (2012) proposed a set of three features to evaluate these interactions in the public sector: transparency, participation and collaboration. Transparency in SM can be obtained by a one-way communication style that pushes information in the name of education. Some metrics to evaluate transparency are posts' likes, for example. Participation involves twoway communication encouraging SM visitors to frequent the government's website. Metrics to evaluate participation involve click-through, page views and number of comments. Collaboration is related to citizens' content co-creation, and is then based on direct interaction with governments. The public should be able to see that their input has influenced government policies. A way to measure collaboration involves analysing shares and comments. The work of Zavattaro et al. (2015), for example, analysed the aforementioned Mergel's points in US local government entities via Twitter.

Initial studies (Sandoval-Almazan and Gil-Garcia, 2012; Ellison and Hardey, 2014) performed survey analysis to ask LGOs directly about the use and importance of SM for citizens' participation, while more recent researchers collected data from the Web and mostly applied descriptive statistics to analyse the interactions (Reilly and Hynan, 2014; Bellstrom et al., 2016). Few works adopt textual analysis and topic modelling (Arunachalam and Sarkar, 2013; Bonsòn et al., 2015), while different researchers also investigated the public's sentiments (Hofmann et al., 2013; Zavattaro et al., 2015; Hubert et al., 2018; Durahim and Coşkun, 2015; Arunachalam and Sarkar, 2013; Naiknaware et al., 2017). The literature review (Table 1) also reports research proposed by Reilly and Hynan (2014), who explored sustainability topics on SM, but with respect to corporations and not to government. Reddick et al. (2017) focussed on textual data related to the Solid Waste Management Department of San Antonio City, Texas.

To the best of our knowledge, ours is the first work that analyses disclosure of environmental matters on SM by LGOs.

\subsection{Government-citizen interaction on social media: an organisational legitimacy perspective or dialogic accountability?}

The SM interactions between LGOs and citizens on sustainability issues is a nearly new field of study, as the previous paragraph demonstrates, and the most common theoretical background applied in literature is the organisational legitimacy perspective (Etter et al., 2018; Knox, 2016).

One-way communication between LGOs and citizens on sustainability issues is represented by a voluntary disclosure that traditionally has sustainability reporting as the outcome. The literature recognises the legitimacy concept as the theoretical background to explain public organisations' choice to disclose sustainability issues (Dowling and Pfeffer, 1975; Navarro Galera et al., 2014), where "organisational legitimacy is generally defined as the social acceptance of organisations and their actions" (Etter et al., 2018, p. 61). The process of constructing organisational legitimacy could be seen as a path by which an organisation communicates with its evaluators to meet their expectations in terms of standards and norms. However, this process cannot be considered in a one-way linear 




Disclosure and sentiment analysis

621

Table 1.

Summary of related works on governments' SM interactions 
MEDAR 29,3

\section{2}

direction because it compromises various "sources of legitimacy - evaluators" (Etter et al., 2018, p. 63) that could have different criteria and perspectives.

Thus, the approach of disclosing "something" to "someone" in a monological way has to be compared to a dialogic accountability system (Brown, 2009; Brown and Dillard, 2013a, 2013b; Manetti and Bellucci, 2016; Bellucci and Manetti, 2017), where "the rights and responsibilities of the constellation of constituencies. . . affected by an account provider's actions" (Dillard and Vinnari, 2019) are taken as starting points. In the dialogic process, the identification of who these constituencies are, and their interests and needs for information, comes not from the organisation but is a recognition from outside towards the institution. In other words, it could be seen as a sort of "networking engagement" which is different from the stakeholder engagement that is focused from the organisation to the outside, but it is like a civil society request for information towards the entity's actions. In that scenario, there could be different methods and tools that enhance dialogical approaches, as shared platforms, "scenario workshops, deliberative mapping, multicriteria analysis, open space technologies, Q methodology and dissensus conferences" (Bellucci et al., 2019 citing Brown and Dillard, 2014).

Platforms could be seen as one of the tools supporting the dialogical accountability system (Bellucci and Manetti, 2017). Thus, with the advent of SM platforms, citizens have the chance to express judgments/opinions/needs/interests about organisations online (Blankespoor, 2018). This opportunity for comment creates a shared platform where the actions, plans and information of the institutions are under scrutiny in a networked perspective. Through SM "the voices of those most negatively affected by corporate - organisations - activity - that - are notably absent" (Everett, 2004, p. 1079) could express their sentiment in the social context, otherwise not engaged in the process, or the "judgements in social media can be considered as contributing to the coconstruction of organizational legitimacy" (Etter et al., 2018, p. 64). The freedom of writing to and answering posts on SM platforms means, in other words, that everyone can write or post his/her point of view, perceptions, reactions without restrictions and it might be seen as a "potential democratization of online arenas" (Etter et al., 2018, p. 68). The consideration of SM as a potential public arena also requires underlining and considering the limits that SM has. First of all comes the circulation and diffusion of fake news (Allcott and Gentzkow, 2017; Shu et al., 2017; Srauy, 2015). Furthermore, SM is primarily a product designed to monetize users' activities, which can affect the visibility and dissemination of content, and is therefore not impartial (Gillespie, 2014). The same problem does not only concern SM but almost all cyberspaces (Dahlberg, 2005). For example, fake news could influence the virtual debate on a certain issue, making the results of the discussion unreliable as a support for dialogic accountability. In other cases, discussion policies on SM can inhibit free discourse on a relevant topic.

The dialogical accountability approach could have two purposes:

(1) The first is a deliberate and legitimate view where "stakeholder engagement is necessary for defining the general consensus among diverse stakeholders or inside a specific category" (Bellucci and Manetti, 2017).

(2) The second is an agonistic view where pluralistic needs are taken into account as various requests for information, dealing with each differently.

The first approach links legitimacy to a rational argument in a public sphere based on Habermas' "ideal speech situation" (Habermas, 1989). This means that SM platforms could have the characteristics of Habermas' "ideal public sphere" because they have the "the potential to increase the symmetrical communication" (Knox, 2016, p. 483) thanks to: 
- the equal opportunity to communicate;

- the same possibility to start a new dialogue, to continue an old one or to express oppositions, explanations, etc.; and

Disclosure and sentiment analysis

- also to inform sentiments or emotions (i.e. likes and hates).

Moreover, the communication is bidirectional, instant or not, and it is transparent that SM is a place for sharing knowledge (Mergel, 2012). In Habermas' ideal of authentic communication, SM characteristics could create a "communicative rational justification of validity claims by public administrators to citizens, unlike rhetoric" (Knox, 2016, p. 488).

The first purpose of dialogic capabilities is to create a convergent consensus over actions, plans and projects throughout a transparent and constructive discussion in a public sphere. Organisational legitimacy could be seen as the outcome of this process. Otherwise, the second purpose of dialogic accountability is focused on an agonistic model of participation, called "agonistic dialogic accounting" by Brown (2009), Dillard and Yuthas (2013) and Brown and Dillard (2013a, 2013b).

Mouffe's agonistic pluralism theoretical frame describes a pluralistic arena where stakeholder engagement is the collection of various standpoints that public organisations/ politics must take into account in their plans from an agonistic, not antagonistic, perspective (Mouffe, 1999, 2000). This means that citizens with divergent opinions or values are not enemies but adversaries, as Mouffe wrote in 2000:

[... . modern democracy's specificity lies in the recognition and legitimation of conflict and the refusal to suppress it by imposing an authoritarian order. This requires providing channels through which collective passions will be given ways to express themselves over issues, which, while allowing enough possibility for identification, will not construct the opponent as an enemy but as an adversary.

SM could have the potential to be one of the possible channels that the public could use to gather this different sentiment, as SM platforms could give the opportunity to express different and contrasting opinions and emotions to a public and wide arena, even if they cannot be considered a "perfect" one for agonistic pluralism because of the limitations mentioned above (fake news, private nature, digital divide, etc.). The agonistic scenario aims to create a wider engagement between parties that results in the reasoning of means and ends in a democratic decision-making process (Bellucci and Manetti, 2017; Vinnari and Dillard, 2016).

The second scenario considers the different "passions" and "to mobilize those passions towards democratic designs" (Mouffe, 2000), while the first aims to take into account the sentiments but, strictly, not incorporate them in the systems' strategies.

Finally, both purposes have a dialogical approach where the engagement and consideration of citizens, community or even non-experts seems to be as relevant as the information and facts disclosed (Brown and Dillard, 2013a, 2013b). In fact, literature calls for new accounting processes that consider the "polyvocal citizenship perspective" (Gray, 1997), the pluralistic nature of contemporary society (Bellucci et al., 2019, Dillar and Ruchan, 2005) and for a more constructionist approach in the social accounting system (Thomson and Bebbington, 2005) that to "engender .... More importantly, societally relevant and meaningful solutions" (Dillard and Vinnari, 2019).

In accordance, this paper aims to contribute to the debate on dialogical accountability using SA applied to public organisations to understand the public's interests and emotions towards LGOs' disclosure of environmental issues, to explore the potential contribution of SM platforms in the construction of a dialogic accountability system and the underlying purpose of that approach. 
MEDAR

29,3

624

\section{Methods}

To study the interactions between LGOs and citizens with regard to ES disclosure via SM, we applied some well-known techniques in the field of natural language processing (NLP) (Manning et al., 1999) and text analysis (Zhai and Massung, 2016). The section is composed of two sub-sections. In Section 3.1, we describe how LGOs' posts were managed, while in Section 3.2, we focus on the analysis of the comments. Figure 1 describes the mind map of the approach followed in this paper.

\subsection{Analysis of local governments' Facebook posts}

The first step of the analysis consists of evaluating LGOs' SM posts. The authors identified five different classes of environmental issues in the context of Italian municipalities: air, energy, territory, water and waste. Appendix 1 explains the classification process, sources and list of keywords used to identify SM posts for each of the five groups.

Starting from the raw Facebook posts, the authors cleaned the text message of numbers, stop words, punctuation and Uniform Resource Locator (URL) references. The text preprocessing was performed using the $n l t k$ module in Python. Then, to obtain an overview of the posts content, we analysed the word frequency. Thus, for each word in a document, the term frequency is computed as follows:

$$
t f_{i, j}=\frac{n_{i, j}}{|d j|}
$$

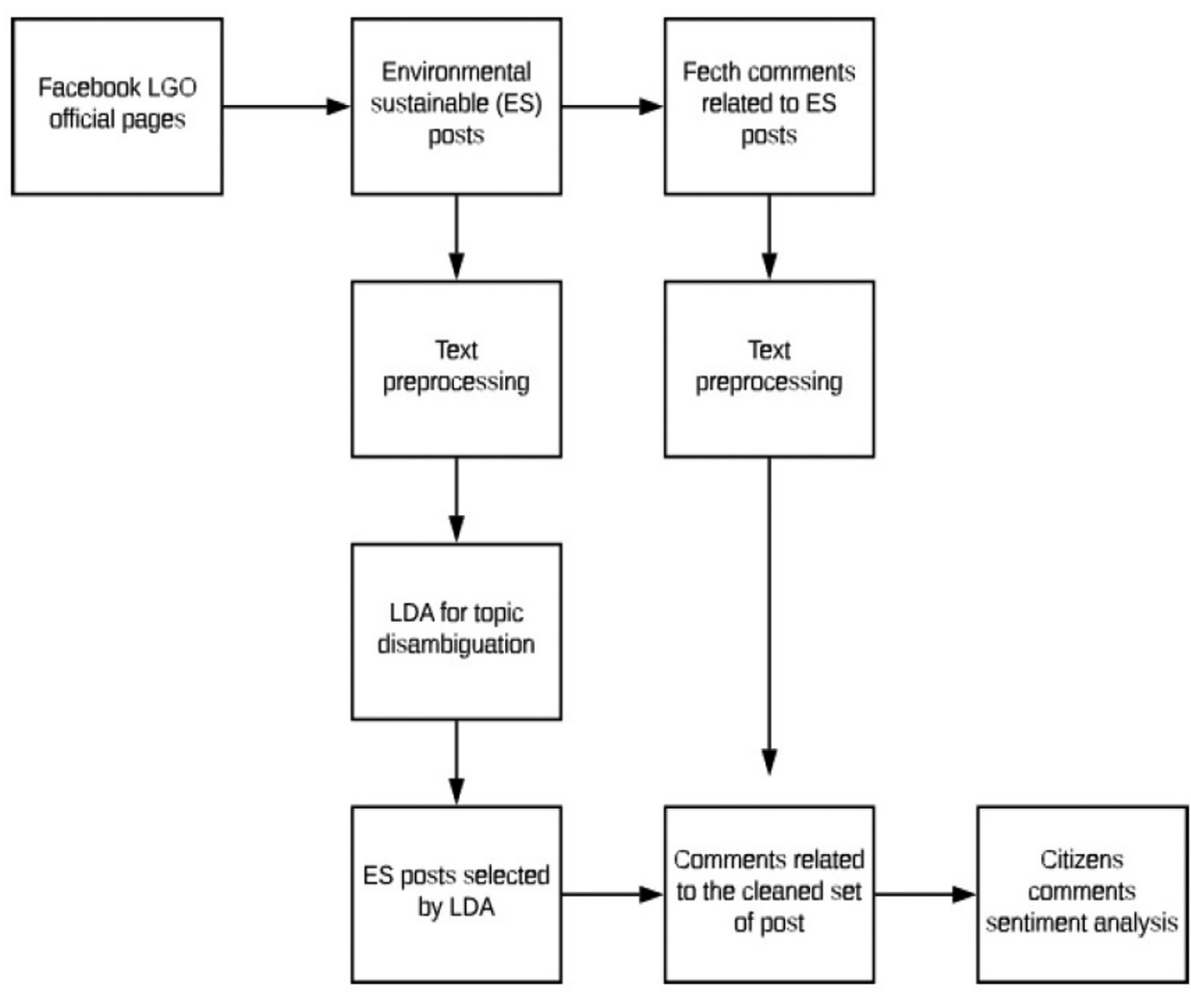

Figure 1. Methodology approach 
where $n_{i, j}$ is the number of occurrences of a word $i$ in the document $j$, and $d_{j}$ is the size of the document $j$ expressed as the total number of words in the document. Analysis of word distribution might be seen as a basic step, but it is useful to understand which topics are included in the document and if there are any out-of-topic posts. In this work, it was crucial to understand whether misleading topics were found in the five classes. To remove posts and relative comments not strictly related to our analysis, we performed topic detection by applying the well-known latent Dirichlet allocation (LDA).

LDA is one of the most common algorithms for topic modelling. It is a statistical method

Disclosure and sentiment analysis to find a mixture of words associated with each topic, and determine the mixture of topics that describe each document. Given the following terms (Blei et al., 2003):

- a word $w$ is the basic unit of text data, indexed by $1, \ldots, V$;

- a document is a sequence of $N$ words denoted by $w=\left(w_{1}, w_{2}, \ldots, w_{N}\right)$, where $w_{N}$ is the $n$-th word in the sequence; and

- a corpus is a collection of $M$ documents denoted by $D=\mathrm{w}_{1}, \mathrm{w}_{2}, \ldots, \mathrm{w}_{M}$.

It is common to model each document $w$ as a distribution $\Theta(w)$ over $K$ topics, and each topic $z_{j}, j=1, \ldots, K$ as a multinomial distribution $\Phi(j)$ over the set of words $W$. To discover the set of topics in each document in a corpus $D$, it is necessary to estimate $\Phi$ and $\Theta$. LDA assumes the following generative process for each document $w$ in a corpus $D$ (Blei et al., 2003):

- Choose $N$-Poisson $(\beta)$; and

- Choose $\Theta-\operatorname{Dir}(\alpha)$.

For each of the $N$ words $w_{N}$ :

- choose a topic zn $\sim$ multinomial $(\Theta)$; and

- choose a word $w_{N}$ from $p\left(w_{N} \mid z_{n}, \beta\right)$, a multinomial probability conditioned on topic $z_{n}$.

In this work, before implementing LDA, the text was stemmed. Stemming is an NLP technique used to reconduct words to their roots by removing affixes (prefixes and suffixes) (Manning et al., 1999). Stemming was implemented using the nltk module available on Python to perform the Snowball Stemmer (Porter, 2001).

The only parameter required to compute LDA is the number of topics $k$. To identify $k$, we used the FindTopicNumber function implemented in the R package datuning. To determine the best number of topic $k$ for each sustainable class $i$, the authors evaluated two metrics for

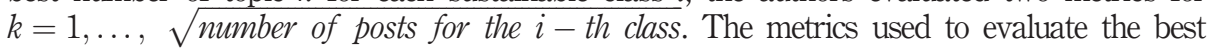
value for $k$ are:

- Griffiths and Steyvers (2004) metric: The authors evaluated the consequences of changing the number of topics $k$ using the Gibbs sampling algorithm to obtain samples from the posterior distribution over $z$ at several choices of $k$ (minimisation criterion).

- Arun et al. (2010) metric: The measure was computed in terms of symmetric KLdivergence of salient distributions derived from the matrix factor, and it was observed that the divergence values are higher for a non-optimal number of topics (maximisation criterion).

Once the LDA has been implemented for each environmental class (air, energy, territory, water and waste), the authors dropped the topics not strictly related to the research purpose. Thus, the authors identified the final sample of LGOs' posts and their relative comments by discarding the misleading ones. 
MEDAR

29,3

626

\subsection{Citizens' comments analysis}

The method applied to study citizens' comments and interactions with LGOs is SA. It is also called opinion mining and uses computational methods to automatically analyse human opinions, sentiments and evaluations of entities such as products, services and organisations (Liu, 2012). SA typically focuses on one specific domain at a time, such as hotels (Shi and Li, 2011), movies (Tripathy et al., 2017) or financial markets (Krishnamoorthy, 2018).

There are two main sentiment classification methods: lexicon and machine learning (ML)-based. A lexicon is a special dictionary in which words are assigned to sentiment scores (Ghosh and Kar, 2013; Kumar et al., 2016). The main advantage is that, once a lexicon is built, a fast unsupervised sentiment classification is achieved by summing the overall word scores. Thus, there is no need for labelled data. Moreover, in some cases, specific adhoc lexicons are created for a target domain (Grabner et al., 2012). However, lexicons tend to produce lower performances when compared with supervised machine-learning approaches. Thus, ML is widely used for SA (Pang et al., 2002; Salvetti et al., 2004; Pouransari and Ghili, 2014). Sentiment classification studies initially explored simpler feature engineering (e.g. Ngrams or bag-of-words) and machine-learning algorithms (e.g. naive Bayes [NB] and support vector machines [SVMs]). After 2014, recent text classification advances, such as word embedding and deep learning (Goodfellow et al., 2016), were naturally incorporated into SA works (Ortigosa et al., 2014; Lai et al., 2015; Conneau et al., 2017). Recently, Zola et al. (2019) proposed a cross-source cross-domain sentiment classification method based on a domainadaptation approach which aims to classify the sentiment of unlabelled data from Web 2.0, passing through other already labelled data from Web sources.

Table 2 reports a brief summary of previous works in sentiment classification considering different domains from websites to social networks. The columns: L lemmatisation, $\mathrm{S}$ - stemming and $\mathrm{P}$ - part-of-speech (POS) tagging identify specific type of text pre-processing commonly used in NLP.

This paper describes SA of citizens' Facebook comments. In comparison to other SM, Facebook comments do not have any limits on the number of characters. Moreover, as mentioned above in the Introduction, a wide range of analysis for LGO-citizen interactions has previously focussed on Facebook, which is, to date, the SM platform with the highest number of daily active accounts, and thus the SM with the highest worldwide coverage (www.statista.com/statistics/272014/global-social-networks-ranked-by-number-of-users/).

However, people tend to use a lot of slang (Golia and Zola, 2019) on blogs and microblogs. This freedom in writing involves many problems for sentiment computation. In this work, the authors decided to apply two SA approaches: lexicon database (LD) and ML. The two approaches were tested separately to propose a double sentiment verification overcoming the drawbacks of the two methods reported in Section 3.2. In fact, if $\mathrm{LD}$ approaches are fast, they are not able to catch the so-called cyber-slang, while ML methods of computation are more expensive but offer greater flexibility.

Before implementing any SA, the comments text was first cleaned to remove stop-words and URLs as previously done for the LGOs' posts. Moreover, the authors performed a POS tagging to identify and remove comments that are composed only of "tags". In SM, tags identify a "call", where a user $a$ "calls" user $b$ or $n$ users, therefore using a POS tagger we can identify comments including only proper nouns and remove them, as a tag does not involve any kind of feeling/sentiment. To perform the POS tag, the authors used the RDRPOSTagger (Nguyen et al., 2014) library developed in the R software. The RDRPOSTagger supports Italian language and is faster in tagging than other POS taggers, such as Treetagger (Schmid, 2013), available in Python. Once the comments have been cleaned, the study also distinguishes 


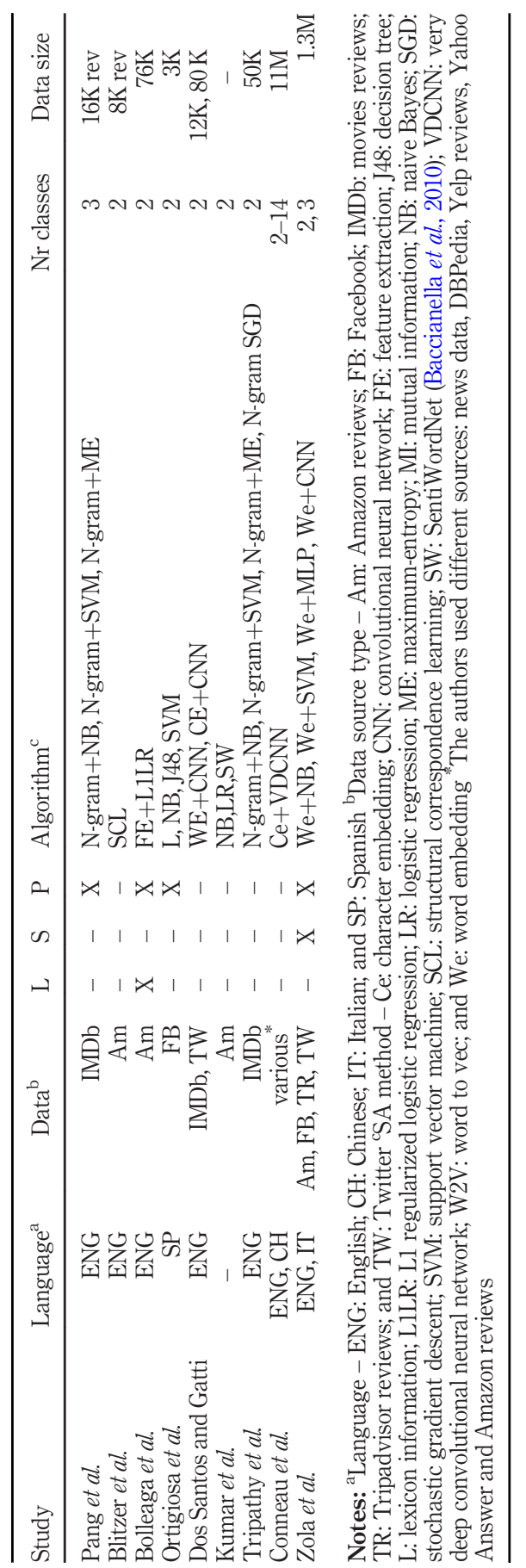

Disclosure and sentiment analysis

Table 2. Summary of related works on SA 
MEDAR 29,3

\section{8}

between citizens' comments and LGOs replies to stakeholders. The sentiment is then computed only with respect to citizens' comments.

Lexicon database. The $\mathrm{LD}$ used in this analysis is the nrc lexicon proposed by Mohammad and Turney (2010). They created the word-emotion association lexicon through Amazon Mechanical Turk. The initial nrc lexicon was developed for English language and later extended to other languages such as Italian. Mohammad and Turney (2010) used Rogets Thesaurus as the source for terms, annotating 14,000 unique English words. The words are then separated into eight categories corresponding to eight emotional and semantic clusters denoted as joy-trust, sadness-anger, surprise-fear and anticipation-disgust, composed of four opposite pairs. Eight features under the nrc lexicon are joy, sadness, anger, fear, trust, disgust, surprise and anticipation. The authors implemented an LD SA using the syuzhet package in R software.

Machine learning: There are a large number of SA models based on ML or deep-learning techniques. In our research, we performed the analysis applying the Zola et al. (2019) algorithm, which is mainly based on a domain adaptation logic in which sentiment from well-known Web sources is useful for defining the feelings within SM sentences. The authors investigated four ML models: NB, SVM, deep multilayer perceptron (MLP) and convolutional neural networks (CNNs) for sentiment classification of SM messages on Facebook and Twitter. The best model is based on a CNN where the textual strings are handled by word embedding (Mikolov et al., 2013). For the Italian case, before applying the word-embedding, the text was stemmed (Manning et al., 1999). An example of stemming in Italian is the word "bellissima" that is synthetized by its root "bell". The sentiment derived is both binary (negative and positive) and multiclass (negative, neutral and positive), and the original research has been conducted both in English and Italian. We decided to apply Zola et al.'s (2019) algorithm because the data are from Facebook Italian pages and, in the original paper, the results pertinent to Facebook comments in Italian showed good performance.

\section{Findings}

\subsection{Data sample}

The sample of Italian LGOs evaluated is reported in Table 3. The study analysed the Italian municipalities with a population of more than 100,000. However, not all Italian municipalities with more than 100,000 citizens are in the sample, as some cities do not have an official Facebook page. As reported in Section 3.1, the authors identified five environmental topics among the overall LGOs posts (Appendix 1).

The textual data in this work are directly downloaded from the Facebook LGOs' public pages using Python script. For each LGOs' page, the authors recorded information about the posts written by the LGOs as well as the likes, shares and comments expressed by citizens. The period varied according to the LGOs' SM activity. The ending date for every LGO is the end of July 2018. Table 3 reports the municipalities included in the sample and for each class date of the oldest post and the number of posts published between the respective date and 30 July, 2018. The total number of posts considered in the analysis was 5,939.

\subsection{Results}

As described in Section 3.1, the authors started from the distribution of words for each of the five ES classes. This step is fundamental to understanding if there are some possible out-of-topic arguments in the data. Table 4 reports the first ten words extracted by the $t f-i d f$ matrix for each class.

For the air sustainability class, Table 4 shows that the most frequent words are related to pollution from road traffic. The energy topic is mainly related to energy savings and renewable energy. For the territory topic, the most frequent words refer to parks and urban green areas, while for the waste class, the major attention is door-to-door recycling, which 


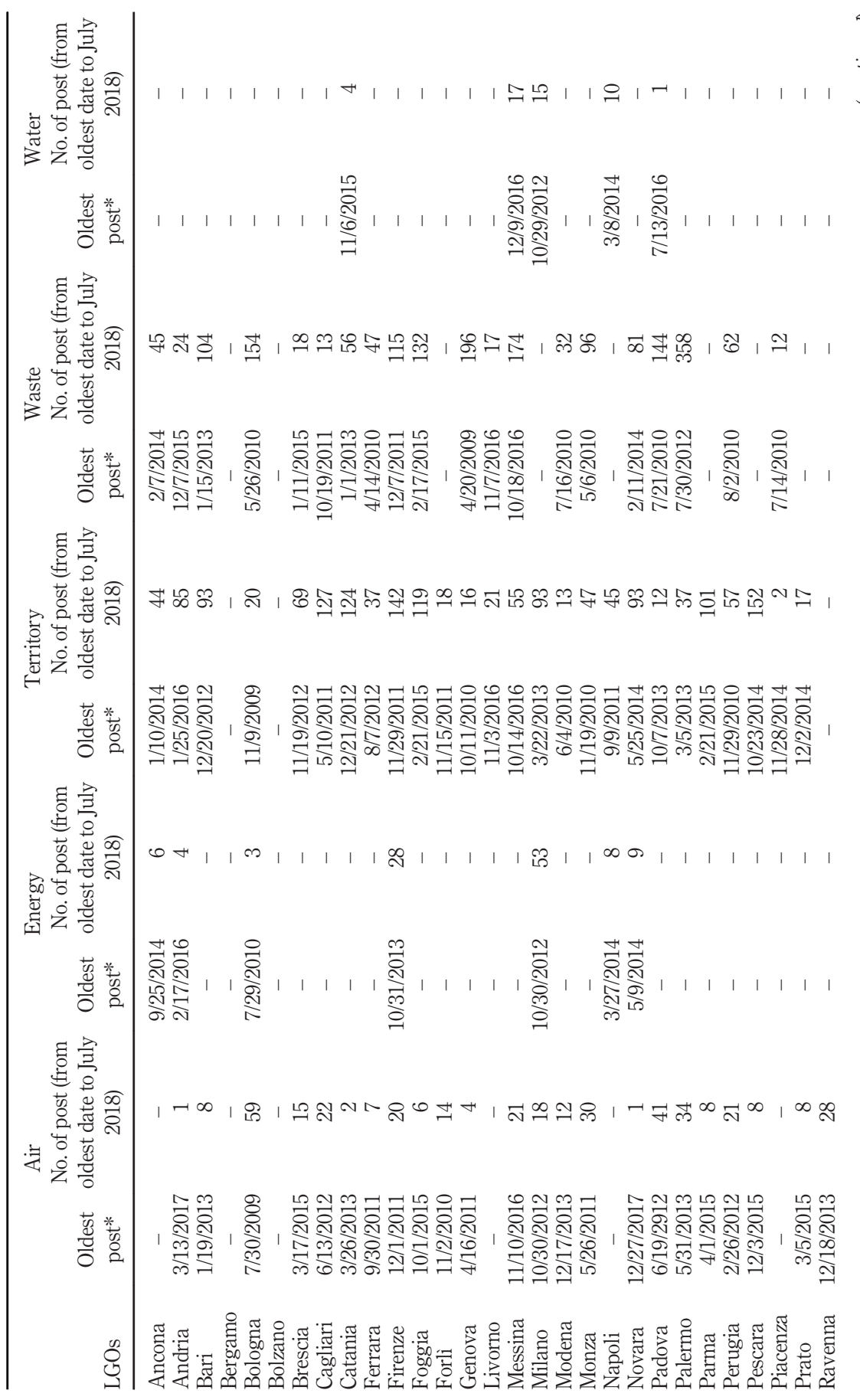

Disclosure and
sentiment
analysis

629

Table 3.

Municipalities analysed 


\section{MEDAR \\ 29,3}

630



Table 3. 
MEDAR 29,3

\section{2}

Figure 2.

Frequency distribution of LGOs' cleaned posts, citizens' comments and LGOs' replies has involved Italian municipalities in recent years. Concluding with the water class, the LGOs' posts are more linked to warnings of work in progress and traffic problems because of water network maintenance.

These findings reveal that there are specific interests in each class. Thus, if we consider, for example, territory, it means we are talking about parks and urban green spaces. This clarifies the meaning that LGOs attribute to sustainability issues.

After evaluating the most frequent words, it was necessary to select topics among LGOs' posts, especially for classes that showed misleading words with respect to ES. Topic detection and classification were performed using LDA (see Methods and Appendix 1), which was performed for all five classes. As reported in Section 3.1, to perform LDA, it is necessary to define the number of hidden topics $k$. To define the best $k$ value for each class, we performed the Griffiths and Steyvers (2004) and Arun et al. (2010) metrics. The results of the two metrics and of the entire LDA process are reported in Appendices 2 and 3.

The LDA allowed out-of-topic posts to be discarded. After these re-elaborations, it was possible to identify the comments of the citizens related only to strictly environmental posts. Before passing through the comment's analysis, it was necessary to distinguish the citizens' messages from the LGOs' replies. Figure 2 reports the frequency of LGOs' posts related to ES issues (without the out-of-topic ones), the distribution of the correspondent citizens' comments and the LGOs' replies. The percentage of citizens' comments is computed proportionally to the amount of LGOs' posts for each class, and the LGOs' reply distribution is computed proportionally to the number of citizens' comments.

These findings reveal the real SM interactions between LGOs and citizens towards each sustainability class. The contribution clearly identifies the direct interactions among the five classes and provides an opportunity to understand if there is a relation, and its frequency. After investigating the degree of interaction between LGOs and citizens on SM, we studied how the public reacts; in other words, what is the sentiment of residents regarding their LGO's disclosure on ES?

As reported in Section 3, SA was performed using two different approaches:

- $L D$ : Use of the $n r c$ lexicon that supports Italian language.

- $M L$ : Use of the domain-adaptation algorithm proposed in Zola et al. (2019).

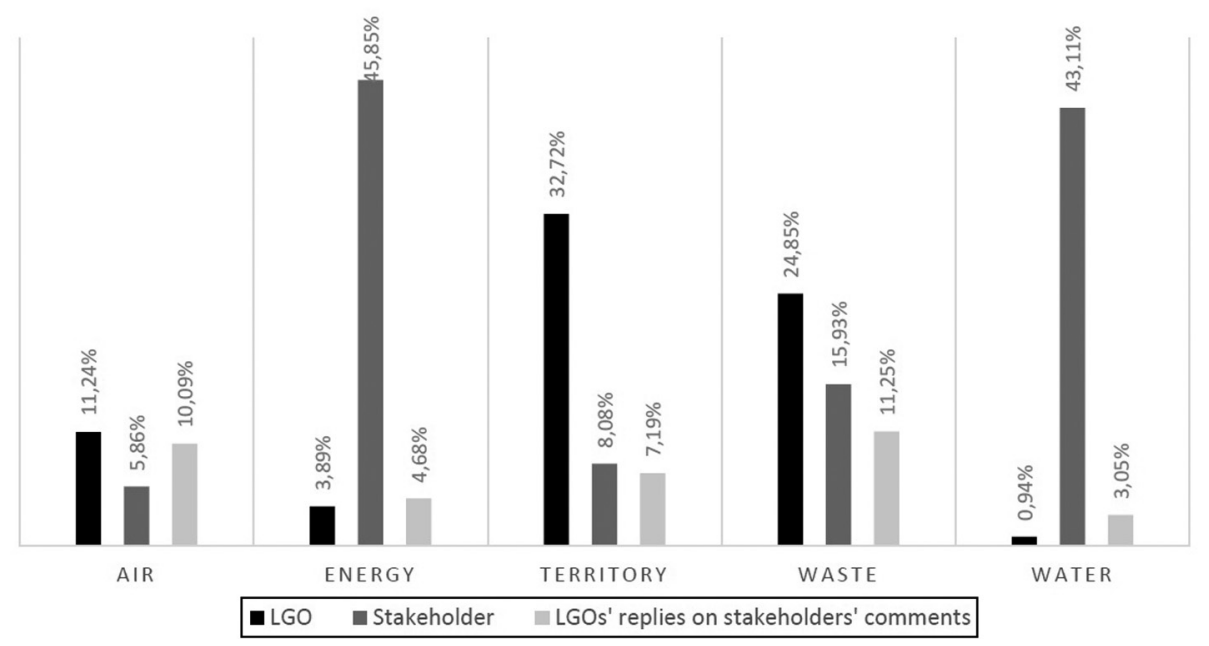


The combined use of these two approaches (the details of the feelings detected are in the Appendix) led to the quantification of public sentiment towards environmental disclosure in three macro-categories (negative, neutral and positive), as reported in Figure 3.

The prevailing sentiment is negative: for every environmental class, more than $50 \%$ of comments express a feeling of dissatisfaction. The lower value for positive emotion is related to the air class (19\%), which is also the class with less public interaction (Figure 3). In contrast, the energy class has a greater number of positive comments (38\%), and is the environmental class in which stakeholders are more active on Facebook. SA contributes to the evaluation of citizens emotions in SM interactions with LGOs and reveals the public's attitudes towards each sustainability class. That approach contributes to study "sentiments" of overall Italian citizens towards each municipality, as a big database.

\section{Discussion of findings}

The first result is that LGOs disclose environmental topics using Facebook and they communicate mostly on territory and waste matters. Thus, they decided to use a social platform to explain their environmental efforts towards a green municipality with parks and public projects, and they would like to disclose more about waste collection and recycling issues. The second finding is that stakeholders are interested in energy and water matters instead; these two classes have the lowest frequency distribution for LGOs.

The choice of using a SM platform to discuss environmental issues - that are not compulsory even in the regulation system with very few voluntary sustainability reports (Giacomini et al., 2018) - could be seen as a chance to talk to citizens on the subject in a shared "public sphere". As stated in the theoretical framework, the SM platform could be a "virtual" place where citizens interact and express their opinions towards LGOs in a networked perspective. This means that the LGOs' decision to create a Facebook public page and thereupon account for environmental facts could be seen as a first attempt to make a dialogical accountability approach because through SM, potentially every citizen could be part of the online arena. In other words, the publics' participation in those arenas is not called by LGOs - they are not specifically engaged in

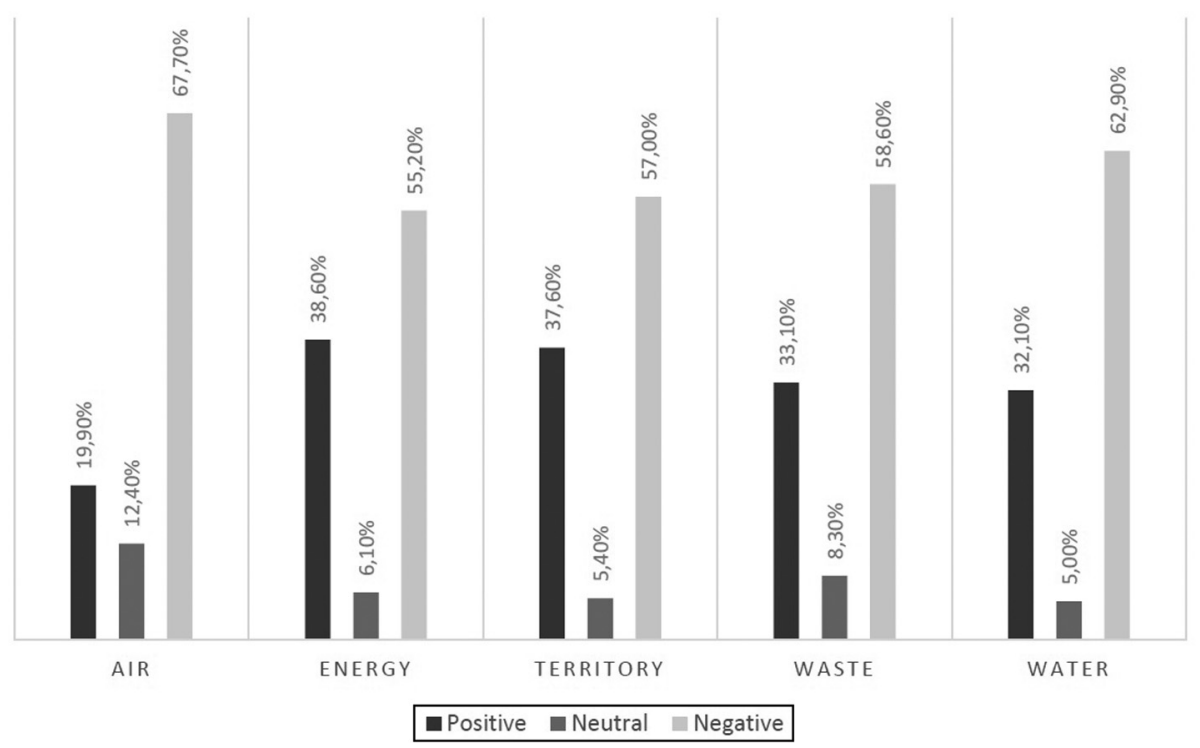

Disclosure and sentiment analysis

633
Figure 3.

SA by cross source cross domain CNN model 
MEDAR 29,3

\section{4}

the process of accountability by LGOs, but from outside, they express their interests and needs for information. According to the dialogic process, citizens could ask for information about the LGO's actions, directly and in instant or non-instant time.

In our findings, it is clear that stakeholders' comments are a request for information about energy and water, not the same as the LGOs' apparent priorities in accountability. The stakeholders' chance to call for energy and water disclosure is the first achievement of an "ideal public sphere" because the SM platform gives:

- citizens the opportunity equal to that of LGOs to discuss environmental issues; and

- to express a different stand on the relevance of environmental topics (Figure 2).

According to the literature (Section 2.2), there are two potential purposes of the dialogical process: deliberative and agonistic. The findings reveal that the number of LGOs' replies to citizens' comments is low (Figure 2), and the highest percentage concerns the waste issue, one of the most relevant from the LGOs' point of view. Thus, the municipalities' behaviour reveals a sort of "communicative rational justification of validity claims by public administrators to citizens" (Knox, 2016), but only on the topics they consider important. This approach can be viewed as a deliberative one, as there is bidirectional information, and the aim to create general consensus, but only on the topics that matter to the LGOs.

Another finding that confirms this dialogical approach is that SM platforms give citizens the opportunity to express their sentiments and emotions about environmental issues as they do in daily life. The first result of the SA, in fact, is that citizens express these feelings in their writing. The second finding in the SA is a critical stakeholder approach that, for every environmental matter, communicates "negative" passions (Figure 3).

One of the most significant classes for citizens is water. In that class, sentiment has one of the highest percentages of negative emotion. On the other citizens' principal topic, energy, their sentiment has the highest percentage of positive emotion. Thus, citizens seem to encourage a constructivist approach (Thomson and Bebbington, 2005) that could be seen as a step-in consensus towards that topic. Air arouses a very high percentage of negative emotion; otherwise, it is not one of the most relevant topics for LGOs or citizens. According to that, Mouffle's agonistic pluralism could be seen as a potential scenario in which findings are valorised by LGOs and citizens towards open discussions on sustainability behaviours, and future actions and plans in a participatory way. The previous result about air, in a hypothetical agonistic pluralism scenario (Mouffle, 2000), would be considered by LGOs to understand how to answer citizens claims for air discussion. For example, the municipality could account for the actions to be taken to reduce PM10 in the air (as this is one of the words in that topic, Table 4), even if this is not the most relevant topic for citizens; thus, it could not focus on the consensus way but open up the disclosure system around future actions and plans. At the time of our study, this was not happening. Moreover, the intrinsic limits of SM platforms are to be considered in this scenario.

To synthetize the divergence between environmental disclosure of LGOs and citizens' interactions, Figure 4 graphically describes the distance in the values of the frequency distributions of LGOs 'cleaned up posts and citizens' comments, reworked from 0 to 1.

\section{Conclusion}

Recently, SM has transformed the scope of organisational communications and created opportunities for unprecedented interaction. At the same time, environmental disclosure is an important and growing area of research in accounting literature in light of environmental emergencies afflicting the planet and the continuing interest of stakeholders in this respect (Blankespoor, 2018). In this regard, this study appears to be among the first to examine environmental disclosure via Facebook made by the biggest Italian LGOs and the related stakeholders' sentiment. 


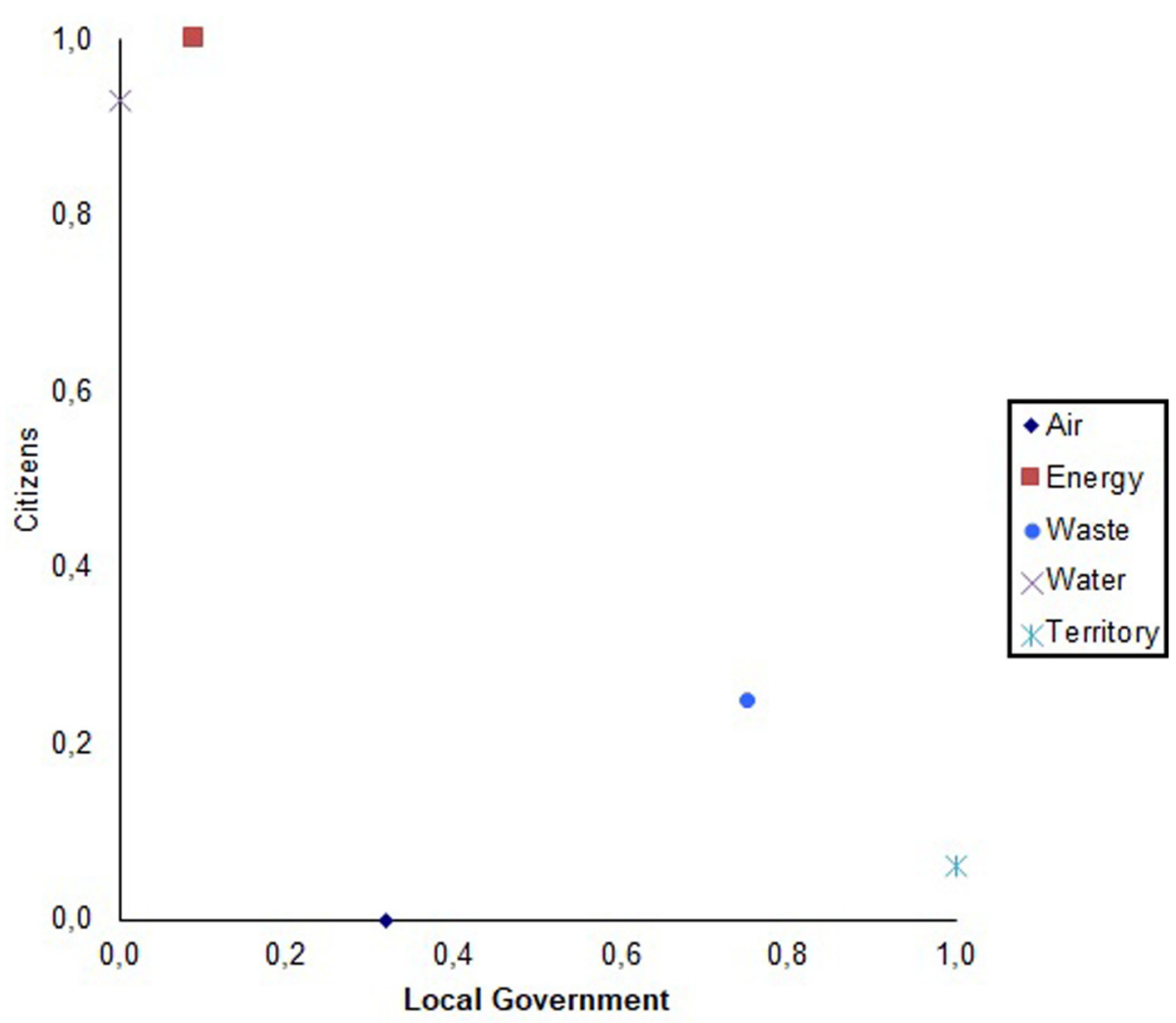

Disclosure and sentiment analysis

The contribution of this research is twofold - first, it demonstrates that LGOs and citizens use SM platforms to discuss environmental issues regarding the municipality. This finding confirms what was previously stated by Blankespoor (2018): at its core, SM is another dissemination channel for organisational communication and, in our study, for environmental matters. However, the characteristics of this channel create different opportunities and risks for management than traditional channels. The low number of responses to public comments also suggests the need for a cultural change in public sector organisations that are still poorly equipped on the issue of participation and engagement. The role of the public administrator should change from that of a neutral expert towards becoming a facilitator of participation and engagement (Brainard and McNutt, 2010). Of course, Facebook is not the only channel for environmental disclosure, but there could also be others such as sustainability reports, municipal websites, conferences and public debates. Future research could compare all these tools to verify their relevance in the environmental communication field, and their strengths and weaknesses.

The second contribution is the statistically tested and validated picture of the relationship between LGOs' behaviour and citizens' sentiment towards environmental topics on a SM platform. The results could represent a dialogical process in its infancy:

- Citizens have a public "virtual" arena in which they could express their interest and opinions towards LGOs environmental communications, without restrictions or directed requests, and they use the Facebook platform as a tool. 
MEDAR 29,3
- However, the divergence between LGOs' disclosure topics and those of the citizens could categorise the purpose of this dialogic approach, as in its first attempt, in a deliberative one.

LGOs do not follow the different citizens' interests, but year after year they decide to communicate in the same direction. This paper considers these posts and comments in a longitudinal way, so the conclusion is that LGOs do not modify the content of their disclosure even if citizens call for something else over time. This could be related to a completely rational argumentation (Manetti and Bellucci, 2016; Knox, 2016) that recognises the way that LGOs behave in the organisational legitimacy process.

Otherwise, the potential of an agonistic pluralistic approach in dialogical accountability must be considered from the LGO perspective - citizens express mainly a negative sentiment, but in a different manner in relation to different topics. The study could also be replicated by each municipality individually to understand the importance the public gives to the topic and thus be aware of their needs - interest and sentiment, each differently. Thus, LGOs could use the same SA as this paper in a more constructive way, using SM platforms to co-construct plans and activities in real life.

In the authors' opinion, the co-construction of a co-accountability scenario to combat climate change and discuss environmental issues could be the goal of the next generation (i.e. millennials) who will be the actors in LGOs as well as citizens. Furthermore, SA could be used by politicians, but also by managers/entrepreneurs in the business sector, to analyse the stakeholders' judgement of their communications/actions and plans with regard to corporate social responsibility. This tool gives a result on-time (i.e. not months or years after, as for the reporting system). It is cheaper than a survey and allows first "photograph" of stakeholders' sentiments. It can also be a useful tool for supporting, developing and improving environmental reporting.

Future research aims to deepen these considerations through qualitative case studies to understand what lies behind the LGOs' disclosure behaviour and why they do not comply with citizens' environmental interests. (Maybe they do not examine that data and they communicate on the basis of perceptions?) The management of comments and interactions is interesting not only from the disclosure strategy aspect, but above all, it is important to understand whether online dialogue with the public actually influences LGOs' strategic choices in the environmental field.

As any piece of research, this paper has some limitations. It is confined to data obtained from a small number of LGOs that restrict generalisability to the sole world of LGOs or to other public sector organisations. Future researchers should emphasise the quantitative inquiry of this study for validation on a broader spectrum and include diverse LGOs of different sizes to ensure the generalisability of the findings in multiple settings and across countries. Furthermore, the limitations of SM - circulation of fake news, private ownership and digital divide - mean that SM cannot be a perfect public arena. While considering these significant limitations, their penetration into the population and their characteristics make SM platforms one of the tools most capable of facilitating dialogue with stakeholders. For this reason, they deserve to be carefully analysed by organisations and scholars.

\section{References}

Allcott, H. and Gentzkow, M. (2017), "Social media and fake news in the 2016 election", Journal of Economic Perspectives, Vol. 31 No. 2, pp. 211-236, doi: 10.1257/jep.31.2.211.

Agostino, D. (2013), "Using social media to engage citizens: a study of Italian municipalities", Public Relations Review, Vol. 39 No. 3, pp. 232-234. 
Agostino, D. and Arnaboldi, M. (2016), “A measurement framework for assessing the contribution of social media to public engagement: an empirical analysis on Facebook", Public Management Review, Vol. 18 No. 9, pp. 1289-1307.

Alam, L. and Lucas, R. (2011), "Tweeting government: a case of Australian Government use of Twitter", IEEE Ninth International Conference on Dependable, Autonomic and Secure Computing, pp. 995-1001.

Arun, R., Suresh, V., Madhavan, C.V. and Murthy, M.N. (2010), "On finding the natural number of topics with latent Dirichlet allocation: some observations", Pacific-Asia Conference on Knowledge Discovery and Data Mining. Springer, pp. 391-402.

Arunachalam, R. and Sarkar, S. (2013), "The new eye of government: citizen sentiment analysis in social media", Proceedings of the IJCNLP 2013 workshop on natural language processing for socialmedia (SocialNLP), pp. 23-28.

Baccianella, S., Esuli, A. and Sebastiani, F. (2010), "Sentiwordnet 3.0: an enhanced lexical resource for sentiment analysis and opinion mining", Lrec, Vol. 10, pp. 2200-2204.

Bellstrom, P., Magnusson, M., Pettersson, J.S. and ThoréN, C. (2016), "Facebook usage in a local government: a content analysis of page owner posts and user posts", Transforming Government: People, Process and Policy, Vol. 10 No. 4, pp. 548-567.

Bellucci, M. and Manetti, G. (2017), "Facebook as a tool for supporting dialogic accounting? Evidence from large philanthropic foundations in the United States", Accounting, Auditing and Accountability Journal, Vol. 30 No. 4, pp. 874-905, doi: 10.1108/AAAJ-07-2015-2122.

Bellucci, M., Simoni, L., Acuti, D. and Manetti, G. (2019), "Stakeholder engagement and dialogic accounting. Empirical evidence in sustainability reporting", Accounting, Auditing \& Accountability Journal, Vol. 32 No. 5, pp. 1467-1499.

Blankespoor, E. (2018), "Firm communication and investor response: a framework and discussion integrating social media", Accounting, Organizations and Society, Vols 68/69, pp. 80-87.

Blei, D.M., Ng, A.Y. and Jordan, M.I. (2003), "Latent Dirichlet allocation”, Journal of Machine Learning Research, Vol. 3, pp. 993-1022.

Bonsòn, E., Royo, S. and Ratkai, M. (2015), “Citizens' engagement on local governments' Facebook sites. An empirical analysis: the impact of different media and content types in Western Europe", Government Information Quarterly, Vol. 32 No. 1, pp. 52-62.

Bremer, S. and Meisch, S. (2017), "Co-production in climate change research: reviewing different perspectives", Wiley Interdisciplinary Reviews: Climate Change, Vol. 8 No. 6, p. e482.

Gillespie, T. (2014), "Facebook's algorithm - why our assumptions are wrong, and our concerns are right", available at: http://culturedigitally.org/2014/07/facebooks-algorithm-why-our-assumptions-arewrong-and-our-concerns-are-right/

Conneau, A., Schwenk, H., Barrault, L. and Lecun, Y. (2017), "Very deep convolutional networks for text classification", Proceedings of the 15th Conference of the European Chapter of the Association for Computational Linguistics: Volume 1, Long Papers, volume 1, pp. 1107-1116.

Brainard, L. and McNutt, J. (2010), "Virtual government-citizen relations", Administration and Society, Vol. 42 No. 7, pp. 836-858.

Brown, J. (2009), "Democracy, sustainability and dialogic accounting technologies: taking pluralism seriously", Critical Perspectives on Accounting, Vol. 20 No. 3, pp. 313-342.

Brown, J. and Dillard, J. (2013a), "Agonizing over engagement: social and environmental accounting and the 'death of environmentalism' debates”, Critical Perspectives on Accounting, Vol. 24 No. 1, pp. 1-18.

Brown, J. and Dillard, J. (2013b), "Critical accounting and communicative action: on the limits of consensual deliberation", Critical Perspectives on Accounting, Vol. 24 No. 3, pp. 176-190.

Brown, J. and Dillard, J. (2014), "Integrated reporting: on the need for broadening out and opening up", Accounting, Auditing and Accountability Journal, Vol. 27 No. 7, pp. 1120-1156. 
MEDAR 29,3

Brundtland Report (1987), Bruntland Report of the World Commission on Environment and Development: Our Common Future, Oslo, available at: www.un-documents.net/our-common-future.pdf

Dahlberg, L. (2005), "The internet as public sphere or culture industry? From pessimism to hope and back", International Journal of Media and Cultural Politics, Vol. 1 No. 1, pp. 93-96, doi: 10.1386/macp.1.1.93/3.

Dillard, J. and Ruchala, L. (2005), "The rules are game: from instrumental rationality to administrative evil", Accounting Auditing and Accountability Journal, Vol. 18 No. 5, pp. 608-630.

Dillard, J. and Vinnari, E. (2019), "Critical dialogical accountability: from accounting-based accountability to accountability-based accounting", Critical Perspectives on Accounting, Vol. 62, pp. 16-38, doi: 10.1016/j.cpa.2018.10.003.

Dillard, J. and Yuthas, K. (2013), "Critical dialogic agonistic pluralism and accounting information systems", International Journal of Accounting Information Systems, Vol. 14 No. 2, pp. 113-119.

Dowling, J. and Pfeffer, J. (1975), "Organizational legitimacy: social values and organizational behavior", The Pacific Sociological Review, Vol. 18 No. 1, pp. 122-136, doi: 10.2307/1388226.

Durahim, A.O. and Coskun, M. (2015), "\# iamhappybecause: gross national happiness through twitter analysis and big data", Technological Forecasting and Social Change, Vol. 99, pp. 92-105.

Ellison, N. and Hardey, M. (2014), "Social media and local government: citizenship, consumption and democracy", Local Government Studies, Vol. 40 No. 1, pp. 21-40.

Etter, M., Colleoni, E., Illia, L., Meggiorin, K. and D’Eugenio, A. (2018), "Measuring organizational legitimacy in social media: assessing citizens' judgments with sentiment analysis", Business and Society, Vol. 57 No. 1, pp. 60-97.

European Union (2014), The 7th Environment Action Programme (7th EAP), available at: www.eea.europa.eu/ data-and-maps/indicators/global-and-european-temperature-9/the-7th-environment-action-programme

Everett, J. (2004), "Exploring (false) dualisms for environmental accounting praxis", Critical Perspectives on Accounting, Vol. 15 No. 8, pp. 1061-1084.

Gesuele, B. (2016), "Municipalities and Facebook use: which key drivers? Empirical evidence from Italian municipalities", International Journal of Public Administration, Vol. 39 No. 10, pp. 771-777, doi: 10.1080/01900692.2015.1034323.

Ghosh, M. and Kar, A. (2013), "Unsupervised linguistic approach for sentiment classification from online reviews using sentiwordnet 3.0”, Int JEng Res Technol, Vol. 2 No. 9.

Giacomini, D., Rocca, L., Carini, C. and Mazzoleni, M. (2018), "Overcoming the barriers to the diffusion of sustainability reporting in Italian LGOs: Better stick or carrot?”, Sustainability, Vol. 10 No. 2, p. 131, doi: 10.3390/su10010131.

Giacomini, D., Zola, P., Paredi, D. and Mazzoleni, M. (2020), "Environmental disclosure and stakeholder engagement via social media: state of the art and potential in public utilities", Corporate Social Responsibility and Environmental Management, Vol. 27 No. 4, pp. 1-13.

Golia, S. and Zola, P. (2019), "A microblog auxiliary Part-Of-Speech tagger based on Bayesian networks", Book of Short Paper, CLADAG 2019.

Goodfellow, I., Bengio, Y., Courville, A. and Bengio, Y. (2016), Deep Learning, Volume 1, MIT press Cambridge.

Grabner, D., Zanker, M., Fliedl, G. and Fuchs, M. (2012), "Classification of customer reviews based on sentiment analysis", Information and Communication Technologies in Tourism, Springer, 460-470.

Gray, R. (1997), "The silent practice of social and environmental accounting and corporate social reporting in companies", in Zadek, S., Evans, R. and Pruzan, P.P. (Eds), Building Corporate Accountability: Emerging Practices in Social and Ethical Accounting Auditing and Reporting, Earthscan, London, pp. 201-217.

Griffiths, T.L. and Steyvers, M. (2004), "Finding scientific topics", Proceedings of the National Academy of Sciences, Vol. 101 No. 1, pp. 5228-5235. 
Habermas, J. (1989), The Structural Transformation of the Public Sphere, Polity Press, Cambridge.

Haro-de Rosario, A., SáEz-Mart"In, A. and del Carmen Caba-PéRez, M. (2018), "Using social media to enhance citizen engagement with local government: Twitter or Facebook? ”, New Media and Society, Vol. 20 No. 1, pp. 29-49.

Hofmann, S., Beverungen, D., Rackers, M. and Becker, J. (2013), “What makes local governments' online communications successful? Insights from a multi-method analysis of Facebook", Government Information Quarterly, Vol. 30 No. 4, pp. 387-396.

Hubert, R.B., Estevez, E., Maguitman, A. and Janowski, T. (2018), "Examining government-citizen interactions on twitter using visual and sentiment analysis", Proceedings of the 19th Annual International Conference on Digital Government Research: Governance in the Data Age, pp. 1-10.

Knox (2016), "Public administrators' use of social media platforms: overcoming the legitimacy dilemma?", Administration and Society, Vol. 48 No. 4, pp. 477-496.

Krishnamoorthy, S. (2018), "Sentiment analysis of financial news articles using performance indicators", Knowledge and Information Systems, Vol. 56 No. 2, pp. 373-394.

Kumar, K.S., Desai, J. and Majumdar, J. (2016), "Opinion mining and sentiment analysis on online customer review", Computational Intelligence and Computing Research (ICCIC), 2016 IEEE International Conference on, IEEE pp. 1-4.

Lai, A. and Stacchezzini, R. (2019), "Special issue "new challenges in sustainability reporting”, Special issue call for papers from Meditari Accountancy Research.

Lai, S., Xu, L., Liu, K. and Zhao, J. (2015), "Recurrent convolutional neural networks for text classification", Proceedings of the Aaci Conference on Artificial Intelligence, Vol. 33, pp. 2267-2273.

Liu, B. (2012), "Sentiment analysis and opinion mining", Synthesis Lectures on Human Language Technologies, Vol. 5 No. 1, pp. 1-167.

Lodhia, S. (2018), "Is the medium the message?: advancing the research agenda on the role of communication media in sustainability reporting", Meditari Accountancy Research, Vol. 26 No. 1, pp. 2-12, available at: https://doi.org/10.1108/MEDAR-08-2017-0197

Manetti, G. and Bellucci, M. (2016), "The use of social media for engaging stakeholders in sustainability reporting”, Accounting, Auditing and Accountability Journal, Vol. 29 No. 6, pp. 985-1011.doi: 10.1108/AAAJ-08-2014-1797.

Manetti, G., Bellucci, M. and Bagnoli, L. (2016), "Stakeholder engagement and public information through social media: a study of Canadian and American public transportation agencies", The American Review of Public Administration, Vol. 47 No. 8, doi: 10.1177/0275074016649260.

Manning, C.D., Manning, C.D. and Schutze, H. (1999), Foundations of Statistical Natural Language Processing, MIT press New York, NY.

Mergel, I. (2012), Social Media in the Public Sector: A Guide to Participation, Collaboration and Transparency in the Networked World, John Wiley and Sons New York, NY.

Mergel, I. (2013), "A framework for interpreting social media interactions in the public sector", Government Information Quarterly, Vol. 30 No. 4, pp. 327-334.

Mikolov, T., Sutskever, I., Chen, K., Corrado, G.S. and Dean, J. (2013), "Distributed representations of words and phrases and their compositionality", Advances in neural information processing systems, pp. 3111-3119.

Mohammad, S.M. and Turney, P.D. (2010), "Emotions evoked by common words and phrases: Using mechanical turk to create an emotion lexicon", Proceedings of the NAACL HLT 2010 workshop on computational approaches to analysis and generation of emotion in text, pp. 26-34. Association for Computational Linguistics.

Mouffe, C. (1999), "Deliberative democracy or agonistic pluralism?”, Social Research, Vol. 66 No. 3, pp. 745-758, available at: www.jstor.org/stable/i40043707

Mouffe, C. (2000), The Democratic Paradox, Verso, London and New York, NY. 
MEDAR 29,3
Naiknaware, B.R., Kawathekar, S. and Deshmukh, S.N. (2017), "Sentiment analysis of Indian government schemes using twitter datasets", IOSR Journal of Computer Engineering, Vol. 1, pp. 70-78.

Navarro Galera, A., de los Ríos Berjillos, A., Ruiz Lozano, M. and Tirado Valencia, P. (2014), "Transparency of sustainability information in local governments: English-speaking and Nordic cross-country analysis", Journal of Cleaner Production, Vol. 64, pp. 495-504, doi: 10.1016/j.jclepro.2013.07.038.

Nguyen, D.Q., Nguyen, D.Q., Pham, D.D. and Pham, S.B. (2014), "Rdrpostagger: a ripple down rulesbased part-of-speech tagger", Proceedings of the Demonstrations at the 14th Conference of the European Chapter of the Association for Computational Linguistics, pp. 17-20.

Ortigosa, A., Mart"In, J.M. and Carro, R.M. (2014), "Sentiment analysis in Facebook and its application to e-learning", Computers in Human Behavior, Vol. 31, pp. 527-541.

Pang, B., Lee, L. and Vaithyanathan, S. (2002), "Thumbs up?: sentiment classification using machine learning techniques", Proceedings of the ACL-02 conference on Empirical methods in natural language processing-Volume 10, Association for Computational Linguistics pp. 79-86.

Parvez, M., Hazelton, J. and Guthrie, J. (2018), "Measuring for climate actions: a disclosure study of ten megacities", Meditari Accountancy Research, Vol. 26 No. 4, pp. 550-575, available at: https://doi. org/10.1108/MEDAR-08-2017-0192

Porter, M.F. (2001), "Snowball: a language for stemming algorithms",

Pouransari, H. and Ghili, S. (2014), "Deep learning for sentiment analysis of movie reviews”, Technical report, Stanford University.

Rambocas, M. Gama, J. et al. (2013),. "Marketing research: the role of sentiment analysis", Technical report, Universidade do Porto, Faculdade de Economia do Porto Porto.

Reddick, C.G., Chatfield, A.T. and Ojo, A. (2017), "A social media text analytics framework for doubleloop learning for citizen-centric public services: a case study of a local government Facebook use", Government Information Quarterly, Vol. 34 No. 1, pp. 110-125.

Reilly, A.H. and Hynan, K.A. (2014), "Corporate communication, sustainability, and social media: It's not easy (really) being green”, Business Horizons, Vol. 57 No. 6, pp. 747-758.

Russell, S., Milne, M. and Dey, C. (2017), "Accounts of nature and the nature of accounts. Critical reflections on environmental accounting and propositions for ecologically informed accounting", Accounting, Auditing and Accountability Journal, Vol. 30 No. 7, pp. 1426-1458.

Sakaki, T., Okazaki, M. and Matsuo, Y. (2010), "Earthquake shakes twitter users: real- time event detection by social sensors", Proceedings of the 19th international conference on World wide web, ACM, 851-860.

Salvetti, F., Lewis, S. and Reichenbach, C. (2004), "Automatic opinion polarity classification of movie", Colorado Research in Linguistics, Vol. 17 No. 1, p. 2.

Sandoval-Almazan, R. and Gil-Garcia, J.R. (2012), "Are government internet portals evolving towards more interaction, participation, and collaboration? Revisiting the rhetoric of e-government among municipalities", Government Information Quarterly, Vol. 29, pp. S72-S81.

Schmid, H. (2013), "Probabilistic part of speech tagging using decision trees", New methods in language processing, p. 154.

Shi, H.X. and Li, X.J. (2011), "A sentiment analysis model for hotel reviews based on supervised learning", Machine Learning and Cybernetics (ICMLC), 2011 International Conference on, volume 3. IEEE, pp. 950-954.

Shu, K., Sliva, A., Wang, S., Tang, J. and Liu, H. (2017), "Fake news detection on social media", ACM SIGKDD Explorations Newsletter, Vol. 19 No. 1, pp. 22-36, doi: 10.1145/3137597.3137600.

Srauy, S. (2015), "The limits of social media: what social media can be, and what we should hope they never become", Social Media + Society, Vol. 1 No. 1, doi: 10.1177/2056305115578676.

Suárez-Rico, Y., García-Benau, M. and Gómez-Villegas, M. (2019), "CSR communication through Facebook in the Latin American integrated market (Mila): disclosure, interactivity and legitimacy", Meditari Accountancy Research, Vol. 27 No. 5, pp. 741-760. 
Thomson, I. and Bebbington, J. (2005), "Social and environmental reporting in the UK: a pedagogic evaluation", Critical Perspectives on Accounting, Vol. 16 No. 5, pp. 507-533.

Tripathy, A., Anand, A. and Rath, S.K. (2017), "Document-level sentiment classification using hybrid machine learning approach", Knowledge and Information Systems, Vol. 53 No. 3, pp. 805-831.

Disclosure and sentiment analysis

United Nations Sustainble Development (1992), "United nations conference on environment \& development Rio de Janerio", Brazil, 3 to 14 June 1992 AGENDA 21, available at: https:// sustainabledevelopment.un.org/content/documents/Agenda21.pdf

Unsworth, K. and Townes, A. (2012), "Social media and E-government: a case study assessing twitter use in the implementation of the open government directive", Proceedings of the American Society for Information Science and Technology, Vol. 49 No. 1, pp. 1-3.

Vinnari, E. and Dillard, J. (2016), “(ANT)agonistics: pluralistic politicization of, and by, accounting and its technologies”, Critical Perspectives on Accounting, Vol. 39 No. C, pp. 25-44.

Wirtz, B.W., Daiser, P. and Mermann, M. (2018), "Social media as a leverage strategy for open government: an exploratory study”, International Journal of Public Administration, Vol. 41 No. 8, pp. 590-603.

Zavattaro, S.M., French, P.E. and Mohanty, S.D. (2015), "A sentiment analysis of us local government tweets: the connection between tone and citizen involvement", Government Information Quarterly, Vol. 32 No. 3, pp. 333-341.

Zhai, C. and Massung, S. (2016), Text Data Management and Analysis: A Practical Introduction to Information Retrieval and Text Mining, Morgan and Claypool New York, NY.

Zola, P., Cortez, P., Ragno, C. and Brentari, E. (2019), "Social media Cross-Source and Cross-Domain sentiment classification", International Journal of Information Technology and Decision Making (Making), Vol. 18 No. 5, pp. 1469-1499.

\section{Further reading}

Blitzer, J., McDonald, R. and Pereira, F. (2006), "Domain adaptation with structural correspondence learning", Proceedings of the 2006 conference on empirical methods in natural language processing. Association for Computational Linguistics, pp. 120-128.

Bollegala, D., Weir, D. and Carroll, J. (2011), "Using multiple sources to construct a sentiment sensitive thesaurus for cross-domain sentiment classification", Proceedings of the 49th Annual Meeting of the Association for Computational Linguistics: Human Language Technologies-Volume 1, Association for Computational Linguistics pp. 132-141.

Bonsòn, E. and Ratkai, M. (2013), "A set of metrics to assess stakeholder engagement and social legitimacy on a corporate Facebook page", Online Information Review, Vol. 37 No. 5, pp. 787-803.

dos Santos, C. and Gatti, M. (2014), "Deep convolutional neural networks for sentiment analysis of short texts", Proceedings of COLING 2014, the 25th International Conference on Computational Linguistics: Technical Papers, pp. 69-78.

Hand, L.C. and Ching, B.D. (2011), "You have one friend request" an exploration of power and citizen engagement in local governments' use of social media”, Administrative Theory and Praxis, Vol. 33 No. 3, pp. 362-382.

Kavanaugh, A.L., Fox, E.A., Sheetz, S.D., Yang, S., Li, L.T., Shoemaker, D.J., . . Xie, L. (2012), "Social media use by government: from the routine to the critical", Government Information Quarterly, Vol. 29 No. 4, pp. 480-491.

Tripathy, A., Agrawal, A. and Rath, S.K. (2016), "Classification of sentiment re- views using n-gram machine learning approach", Expert Systems with Applications, Vol. 57, pp. 117-126. 


\section{MEDAR Appendix 1}

29,3

\section{2}

GRI

Limitation of eaviroamental impact:

Reduction of energy consumption;

Energy production from rencwable sources:

Water supply:

Reocled water:

Wastewater Treatment;

Environmental imestments.

Figure A1.

Sources of the five environmental classes (Global Reporting Initiative guidelines and indicators for "Fair and sustainable wellbeing”)
NSII Fair and sustainable well-being indicators

Emissions of $\mathrm{CO} 2$ and other altering climate gases:

Conferment of urban waste to landfill;

Urban air quality.

Awallability of parics:

Contaminated sites;

Areas with hydrogeological problems:

Protected areas;

Concern for the loss of biodiversity:

Separate collection of municipal waste.
5 areas identified:

\section{Air}

2. Energy

3. Territory

4. Waste

5. Water 

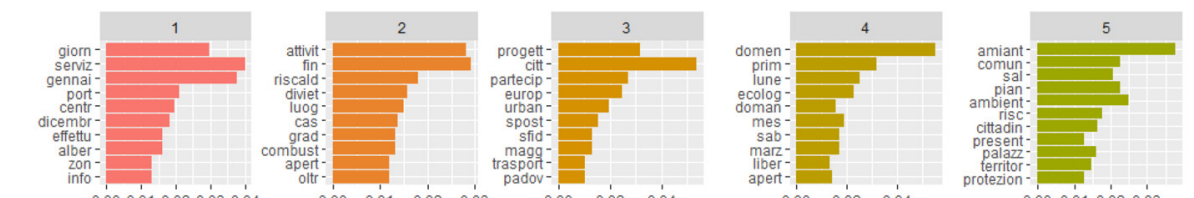

analysis
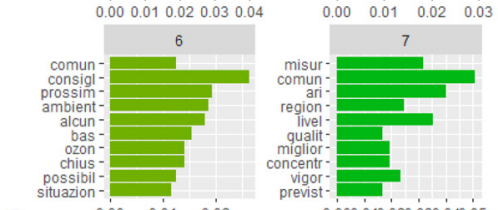

$\begin{array}{lll}0.00 & 0.02 & 0.04\end{array}$

$\stackrel{E}{ \pm}$

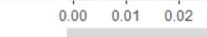

0.000 .010 .020 .030 .040 .05
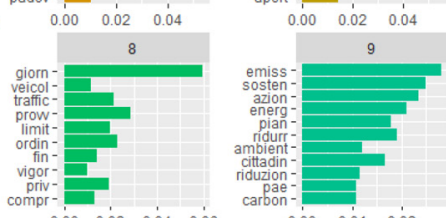

$\begin{array}{lllll}0.00 & 0.01 & 0.02 & 0.03\end{array}$

643
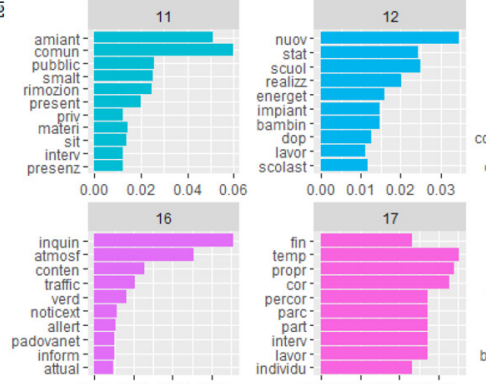

$\begin{array}{llll}0.00 & 0.02 & 0.04 & 0.06\end{array}$
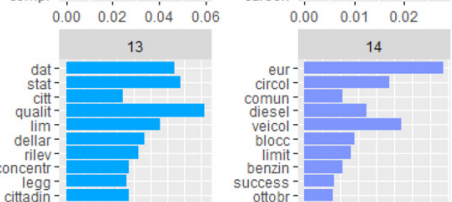

limit-

benzin-
success-
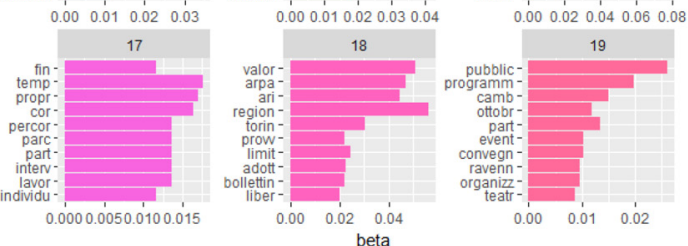

Figure A2. LDA - AIR 


\section{MEDAR \\ 29,3}

\section{4}

Figure A3.

LDA - ENERGY

Figure A4.

LDA - WASTE
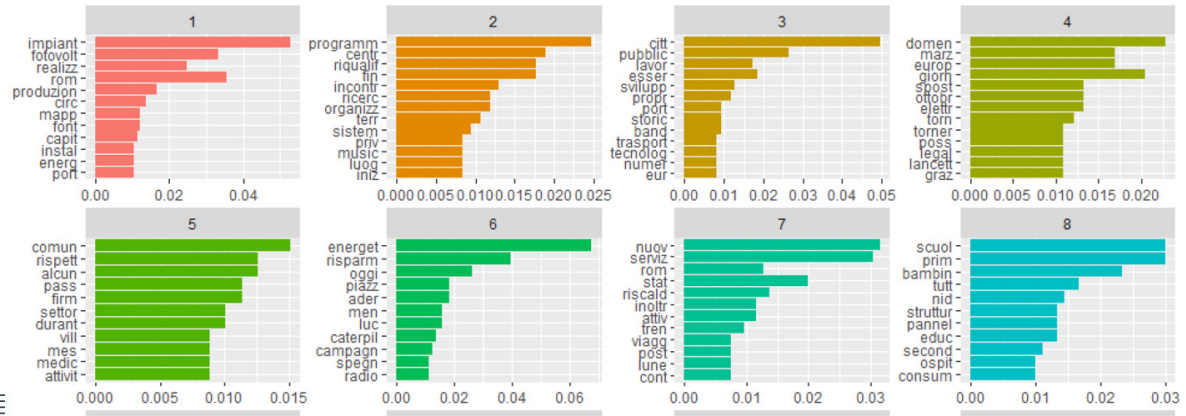

E
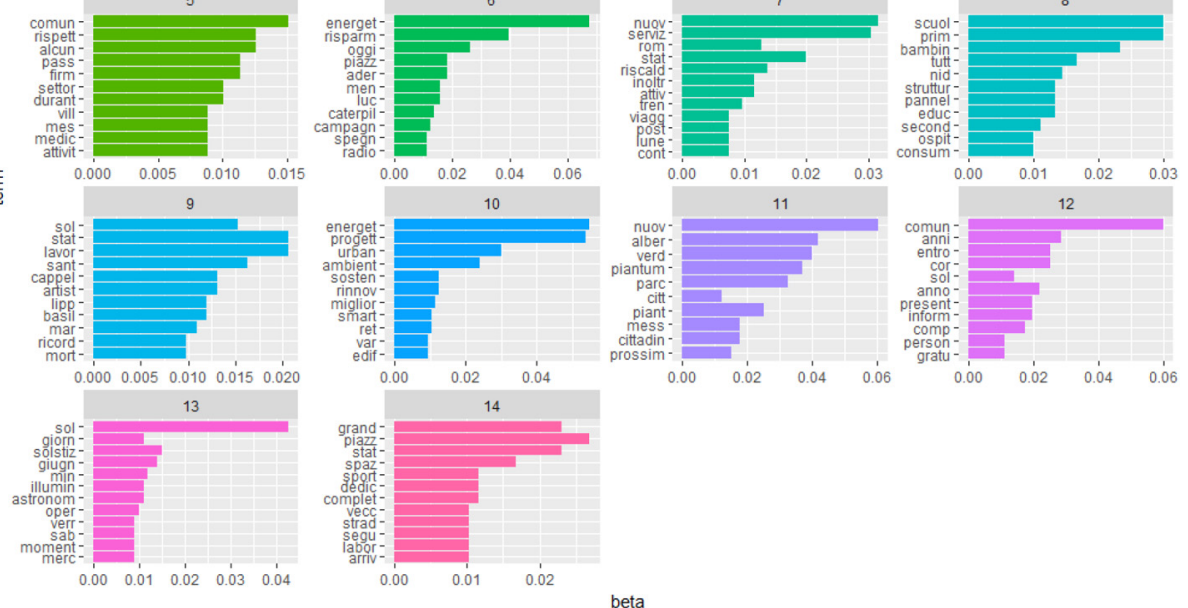
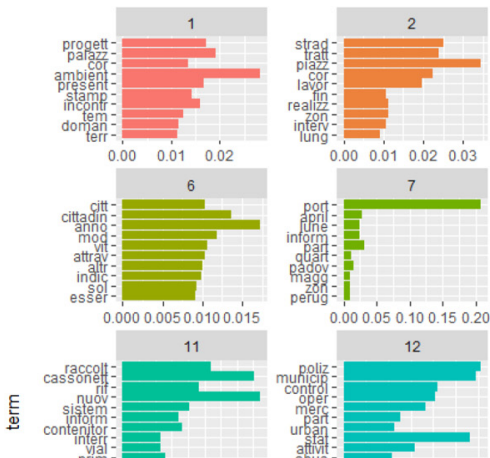

0.000 .050 .100 .150 .2
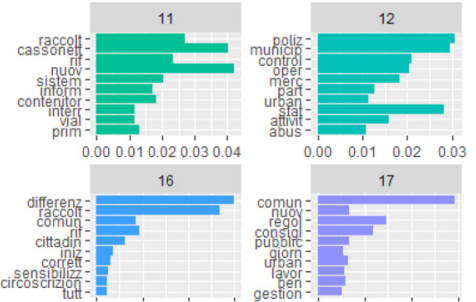

$\begin{array}{llll}0.00 & 0.05 & 0.10 & 0.15\end{array}$

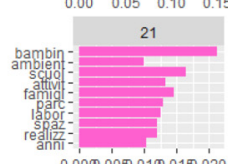

0.0. $0.04 \quad 0.05$

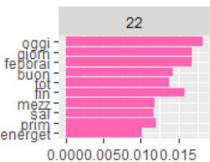

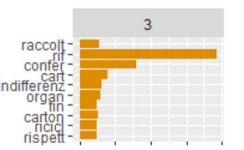
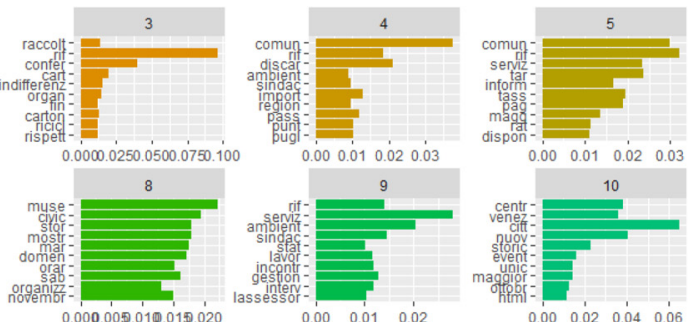

$\begin{array}{llll}0.00 & 0.02 & 0.04 & 0.06\end{array}$
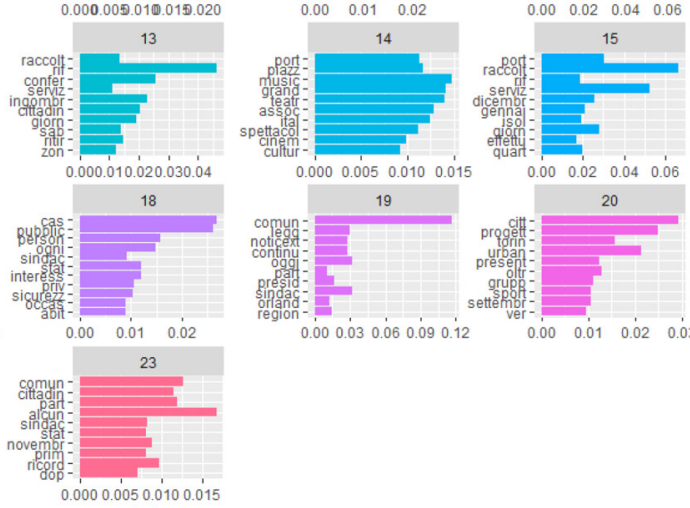

0.000 .030 .060 .090 .12

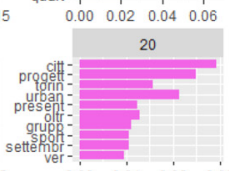

$\begin{array}{llll}0.00 & 0.01 & 0.02 & 0.03\end{array}$ 

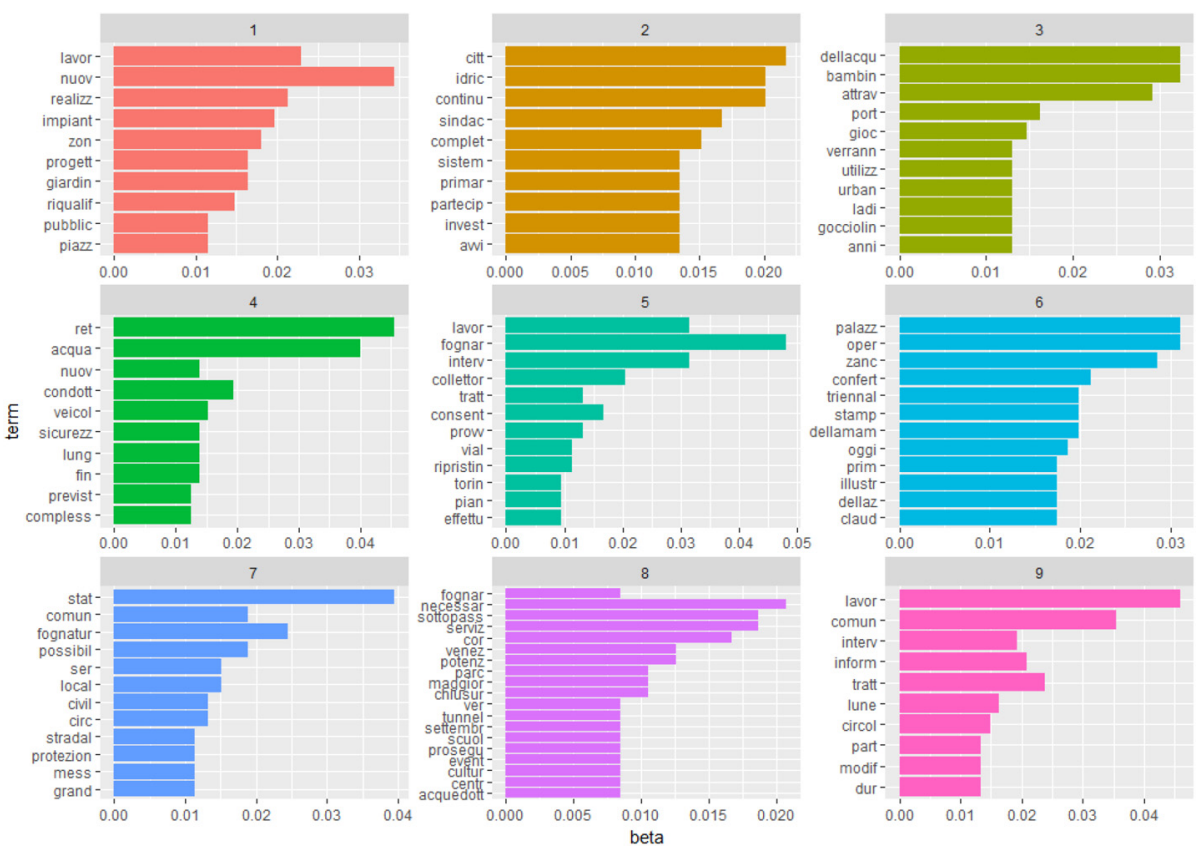

Disclosure and sentiment analysis

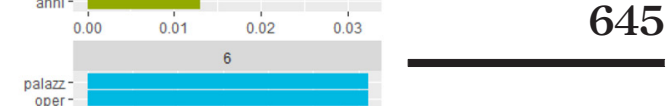

Figure A5. LDA - WATER
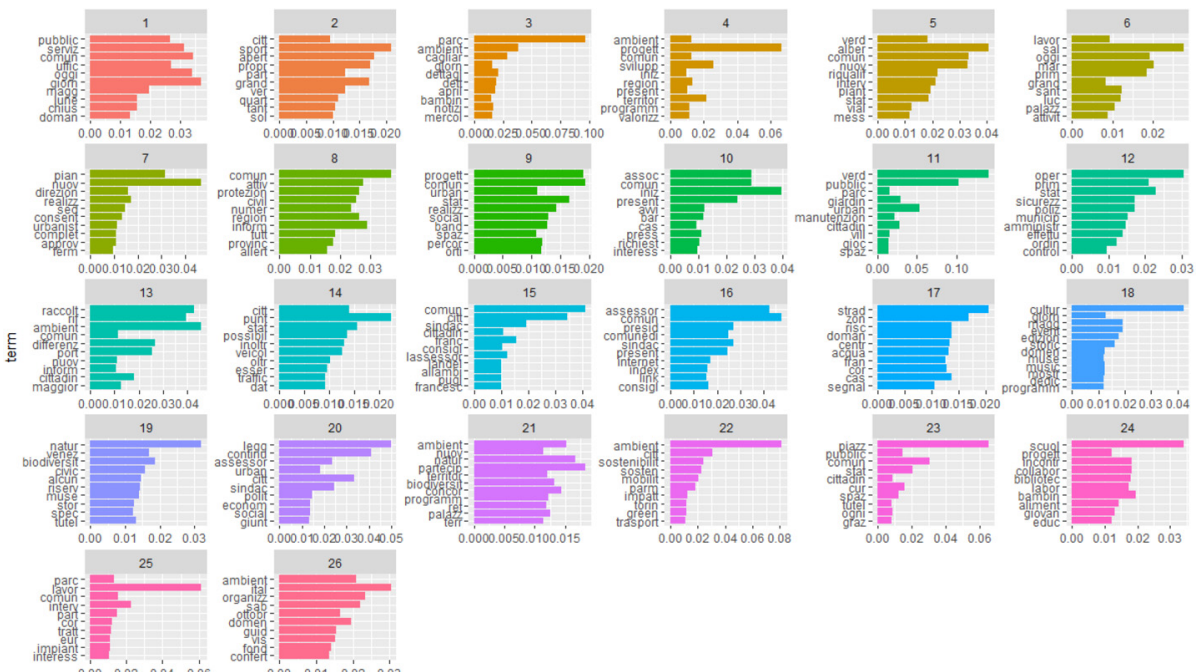

Figure A6.

$000 \quad 002004 \quad 006$
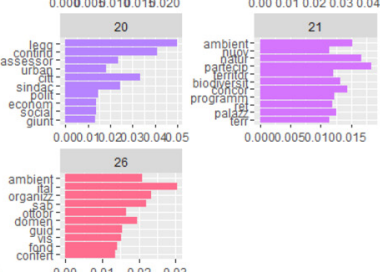

$\begin{array}{llll}0.00 & 0.01 & 0.02 & 0.03\end{array}$

LDA - AIR 
MEDAR

29,3

646

Environmental

sustainability area

Topic excluded

Air

Energy

Waste

$1,6,17,19$

Table A1.

Water

Territory

$1,2,4,6,7,8,10,11$

$3,4,5,7,8,9,11,13,19,21,22,24,26$

$1,3,4,5,9,11,13,15,16,20,21$

LDA

\section{Appendix 3}

Table A2.

Lexicon dictionary

SA

\begin{tabular}{lccccc}
\hline & Air $(\%)$ & Energy $(\%)$ & Territory (\%) & Waste (\%) & Water (\%) \\
\hline Anger & 10.7 & 9.4 & 9.1 & 8.9 & 8.4 \\
Anticipation & 14.6 & 12.7 & 14.6 & 14.3 & 12.4 \\
Disgust & 10.0 & 6.8 & 8.3 & 12.1 & 9.0 \\
Fear & 13.1 & 11.3 & 10.6 & 10.2 & 13.2 \\
Joy & 10.4 & 14.0 & 14.3 & 11.1 & 11.6 \\
Sadness & 14.2 & 14.3 & 13.6 & 15.7 & 17.4 \\
Surprise & 6.1 & 6.8 & 6.4 & 5.3 & 6.9 \\
Trust & 20.9 & 24.7 & 23.1 & 22.5 & 21.2 \\
\hline
\end{tabular}

Corresponding author

Laura Rocca can be contacted at: laura.rocca@unibs.it

For instructions on how to order reprints of this article, please visit our website:

Or contact us for further details: permissions@emeraldinsight.com 